\title{
Myelomeningocele: approach and treatment alternatives, based on the evidence provided by gait analysis
}

\begin{abstract}
Myelomeningocele results from failure of the neural tube to close in the developing fetus and is associated with neurological impairment (Incidence 1:1000 births). The level of the anatomic lesion generally correlates with the neurological deficit and ranges from complete paralysis to minimal or no motor deficit. Myelomeningocele or Spina bifida can lead to health problems, physical disabilities and learning problems. Generally associated paralysis of the lower extremities and sphincters control absence. Treatment includes surgery, braces or other corrective devices, physical therapy. The functional classification that concerns us in this review includes three types.
\end{abstract}

Keywords: spina bifida, myelomeningocele, hypertrichosis and open lesions, sphincters
Volume 12 Issue I - 2020

\author{
Marcel Rupcich G,' Ricardo J Bravo $2-4$ \\ 'Pediatric Orthopaedic Service, Centro Médico Docente La \\ Trinidad, Venezuela \\ ${ }^{2}$ Center for Assistive Technology, Simón Bolívar University, \\ Venezuela \\ ${ }^{3}$ Neurodevelopment Unit, Residencia Humana, Venezuela \\ ${ }^{4}$ Department of Biomedical Engineering, Polytechnic University \\ of Puerto Rico,Venezuela
}

\begin{abstract}
Correspondence: Marcel Rupcich G, Pediatrics Department, Centro Médico Docente La Trinidad, Caracas, Venezuela, Tel +58-4I 2-3327825, Email marcelrupcic@gmail.com
\end{abstract}

Received: January 30, 2020 | Published: February 27, 2020

\section{Introduction}

The term spinal dysraphism, ${ }^{1}$ refers to those conditions resulting from faulty of development in the midline of the dorsal aspect of the embryo, with resulting bony or neural deformities. Cutaneous lesions are common but not always present which occurs before the third month of life.

Spina bifida belongs to a group of disturbance of development of the vertebral arches or the cranial vault. These are often associated with disorder of developmental of the structures derived from the neural tube and the meninges, and may give rise to cystic formations.

\section{Four types of spina bifida could be described: ${ }^{1}$}

Spina bifida occulta is a localized defect in one or more vertebral arches, presumably developing as a failure of the halves of the vertebral arches to meet and fuse in the third month. The spinal cord and meninges remain within the vertebral canal.

Myeningocele, is a cystic swelling of dura and arachnoid protrudes through a defect in the vertebral arches under the skin and it is filled with fluid. The spinal cord is entirely confined to the vertebral canal, but may exhibit abnormalities.

Myelomeningocele, is a fluid -filled cystic swelling, formed by dura and arachnoid, protruding through a defect in the vertebral arches under the skin, and the spinal cord and nerve roots are carried out into the fundus of the sac.

Myeloschisis or myelocele is a rare and severe form of spina bifida, vertebral arches are deficient and neural plate material is spread out on the surface, sometimes in a shallow depression, more commonly over a cystic swelling of the meninges. It is most common in the lumbosacral region.
The spectrum of clinical presentation is enormous, ranging from lethal rachischisis to asymptomatic spina bifida occulta with a small lipoma. The diversity of presentations, suggests that the causative factors exert their effects at different periods of development, In addition to genetics and the environment that should be considered. Other associated abnormalities found in spina bifida are: congenital spine deformity, Sprengel deformity, tethered cord, and neurogenic bladder and Talipes equinovarus. Also high risk of latex allergy is present.

Progressive neurological deterioration may occur because hydrocephalus in association with a type II Arnold-Chiari defect common and develops in $80 \%$ of children with myelomeningocele. ${ }^{2-5}$

Within this spectrum are all grades of myelomeningocele, meningocele, diastematomyelia, diplomyelia, fibrous bands, tight film terminale, intra and extradural lipomas, dermoids cysts, neurenteric cysts and congenital malformations of the nerve roots. Skin lesions, include dermal sinus, nevus, hypertrichosis and open lesions.

\section{Functional impact}

Referring to independence in daily life, currently, the mostly accepted classification is the one that emerges from the available motor function, ${ }^{6-8}$ so it must be clear which are the motor resources of the patient, mainly of the antigravity muscles, which is also related to the gait prognosis and maintenance of it over time.

Ambulation is affected also by the age, obesity, spasticity, orthopedic deformities, etc. ${ }^{9}$ The greater the commitment, the greater the disability and implications such as survival, associated deformities and ambulation capacity mainly. Two main factors affect walking ability and extent of bracing in this patient population: motor level and balance. 


\section{Motor level}

Motor classification and implications: The most accepted classification of spina bifida is based on the neurologic level of the lesion (Table 1). ${ }^{6-8}$ Patients are divided into three groups based on lesion level and accompanying functional and ambulatory capacity.
The criterion for classifying patients, depending on the muscle resource present in lower limbs, is summarized in Table 2:

It is important to note that the lesion is asymmetric in most cases, and that the classification may tend to lean towards the more compromised side.

Table I Functional classification for myelomeningocele ambulatory patients

\begin{tabular}{lll}
\hline Group & Level & Comments \\
\hline I & Thoracic/High Lumbar Level & $\begin{array}{l}\text { Thoracic/high lumbar: (minimum lower limb motor resource, short-term ambulation; highest risk of } \\
\text { associated deformities. Approximately } 7 \% \text { become sedentary between } 7 \text { and I0 years of age. } \\
\text { Low lumbar (quadriceps and hamstrings function mainly internal): } 70 \% \text { to } 80 \% \text { maintain walking capacity } \\
\text { at adulthood. } \\
3\end{array}$ \\
Sow Lumbar Level & $\begin{array}{l}\text { Sacral level - they practically have normal gait. } 98 \% \text { maintain walking capacity at adulthood. This group } \\
\text { has been subdivided into two subgroups: }\end{array}$ \\
& - Group I High Sacral & High Sacrum, defined by the absence of plantar flexors and \\
- Group II Low Sacral & Low Sacrum by the presence of usually weak plantar flexors
\end{tabular}

Source: Swank and Dias, $1994^{6}$

Table 2 Muscle resources vs. motor level in Myelomeningocele

\begin{tabular}{llll}
\hline Muscle group & Thoracic/High Lumbar & Low Lumbar & High Sacral \\
\hline Hip flexors & May or may not be present & present & present \\
Hip adductors & May or may not be present & present & present \\
Hip extensors & absent & absent & present \\
Hip abductors & Absent & absent & present \\
K exte & Absent & present & present \\
K flex & Absent & Medial present \& Lateral may or may not & present \\
Ankle plantar flexor & Absent & absent & present \\
Ankle dorsal flexors & absent & absent & present \\
\hline
\end{tabular}

Source: authors

\section{Balance}

Balance also affects walking ability and extent of bracing and is related to the following: ${ }^{10}$ presence or absence of shunt, shunt function, numbers of shunts revisions.

The statistics in the literature of specialized centers, ${ }^{8}$ shown that the $70-80 \%$ of the low lumbar level and the $98 \%$ of the sacral level, retain their independent walking ability in adult life. Thoracic or high lumbar level, $7 \%$ lose the ability to walk between 7 and 10 years. ${ }^{6-8}$

\section{Quality of ambulation}

Factors that affect quality of gait include: ${ }^{11}$ muscle weakness, severe scoliosis, hip flexion contracture, Hip abduction contracture, hip subluxation or dislocation (with or without soft tissue contracture), hip rotational deformities (internal or external), ${ }^{12}$ knee flexion contracture $^{13-15}$ and tibial torsion (internal or external). ${ }^{16,17}$
Since a large percentage of ambulators maintain their ability to walk, the quality of this must be considered. Gait analysis can be used to access and help quantify the quality of gait. ${ }^{9}$

In this review we wanted to show the current state of pathology management based on the known teaching through the gait analysis, in future publications, we will examine more deeply its characteristics and existing orthopedic treatment, which depends on the anatomical level (muscular resources), balance and on the bilaterality (or not) presence.

\section{Overview of treatments}

Spina bifida is a disease with all degrees of severity and difficult decisions must be made in the neonatal period when the child has a severe involvement.

The orthopedic care of patients with spina bifida is both challenging and rewarding. Due to the many medical comorbidities involved, 
careful evaluation and management of these patients should occur as part of a team approach involving members from multiple specialties, including neurosurgery, pediatrics, physiatry, urology, orthotics, physical therapy, and social work. As part of this team, the goal of the orthopedic surgeon should be to minimize deformity and maximize function and mobility, while limiting complications.

\section{Conclusion}

Typically, a clinical assessment of strength alone rarely reflects the asymmetry noted during gait. An instrumented gait analysis is the Standard of Expert Care for children with gait abnormalities secondary to spina bifida. The main objective of diagnostic gait analysis is to define the consequences derived from the neural tube in relation to the functional activity and future independence of the patient.

Instrumented gait analysis can also give physicians a greater understanding of how the neurological deficiency affects walking function, the implications of reduced motor function and further define the functional level of the patient. The current philosophy is to minimize the dependency on orthoses for ambulation during childhood and to optimize mobility and independence within the patient's expectations and functional level. ${ }^{18}$

\section{Acknowledgments}

None.

\section{Conflicts of interest}

Authors have no conflict of interest to declare.

\section{Funding}

None.

\section{References}

1. Menelaus M. The orthopaedic Management of Spina Bifida Cystica. 2nd ed. Edinburgh, New York: Churchill Livingstone; 1980:217.

2. Stein SC, Schut L. Hydrocephalus in myelomeningocele. Childs Brain. 1979;5(4):413-419.

3. Mazur JM, Stillwell A, Menelaus M. The significance of spasticity in the upper and lower limbs in myelomeningocele. J Bone Joint Surg Br. 1986;68(2):213-217.

4. Mazur JM, Menelaus MB, Hudson I, et al. Hand function in patients with spina bifida cystica. J Pediatr Orthop. 1986;6(4):442-447.
5. Roach JW, Short BF, Saltzman HM. Adult consequences of spina bifida: a cohort study. Clin Orthop Relat Res. 2011;469(5):1246-1252.

6. Swank M, Dias LS. Walking ability in spina bifida patients: a model for predicting future ambulatory status based on sitting balance and motor level. J Pediatr Orthop. 1994;14(6):715-718.

7. Dias LS. Myelomeningocele and intraspinal lipoma. In: Sponseller PD, editor. Orthopaedic knowledge update: pediatrics. 2nd ed. American Academy of Orthopaedic Surgeons. 2002:249-259.

8. Swaroop VT, Dias LS. Orthopedic management of spina bifida. Part I: hip, knee, and rotational deformities. J Child Orthop. 2009;3(6):441449 .

9. Baghdadi T, Abdi R, Bashi RZ, et al. Surgical Management of Hip Problems in Myelomeningocele: A review article. Arch Bone Jt Surg. 2016;4(3):197-203.

10. Battibugli S, Gryfakis N, Dias LS, et al. Functional gait comparison between children with myelomeningocele: shunt versus no shunt. Dev Med Child Neurol. 2007;49(10):764-769.

11. Asher M, Olson J. Factors affecting the ambulatory status of patients with spina bifida cystica. J Bone Joint Surg Am. 1983;65(3):350-356.

12. Dunteman RC, Vankoski SJ, Dias LS. Internal derotation osteotomy of the tibia: pre- and postoperative gait analysis in persons with high sacral myelomeningocele. J Pediatr Orthop. 2000;20(5):623-628.

13. Westcott MA, Dynes MC, Remer EM, et al. Congenital and acquired orthopedic abnormalities in patients with myelomeningocele. Radiographics. 1992:12(6):1155-1173.

14. Moen T, Gryfakis N, Dias L, et al. Crouched gait in myelomeningocele: a comparison between the degree of knee flexion contracture in the clinical examination and during gait. J Pediatr Orthop. 2005;25(5):657660 .

15. Dias LS. Surgical management of knee contractures in myelomeningocele. J Pediatr Orthop. 1982;2(2):127-131.

16. Duffy CM, Hill AE, Cosgrove AP, et al. Three-dimensional gait analysis in spina bifida. J Pediatr Orthop. 1996;16(6):786-791.

17. Dodgin DA, De Swart RJ, Stefko RM, et al. Distal tibial/fibular derotation osteotomy for correction of tibial torsion: review of technique and results in 63 cases. J Pediatr Orthop. 1998;18(1):95-101.

18. Thomson JD, Segal LS. Orthopedic management of spina bifida. Dev Disabil Res Rev. 2010;16(1):96-103. 